\title{
AGRESSORES NA VIOLÊNCIA DOMÉSTICA: UM ESTUDO DO PERFIL SÓCIOJURÍDICO
}

\author{
OFFENDERS IN DOMESTIC VIOLENCE: A SOCIO-JURIDICAL PROFILE STUDY
}

\section{RESUMO}

\author{
${ }^{1}$ Anaïs Eulálio Brasileiro \\ ${ }^{2}$ Milena Barbosa de Melo
}

A pesquisa tem como objetivo geral delinear o perfil dos agressores de violência contra a mulher sob um aspecto sociojurídico. Baseou-se no método indutivo, com abordagem quantitativa e qualitativa, tendo como material de base os registros arquivados na Delegacia da Mulher de Campina Grande (PB). O projeto de pesquisa foi aprovado (49416415.2.0000.5175) pelo Comitê de Ética e os dados foram refinados em categorias para melhor análise. O perfil estudado demonstra a necessidade de acompanhamento ao agressor como prevê a Lei, como também maior aparelhamento por parte da Delegacia da Mulher e necessidade de divulgação sobre Medidas Protetivas.

Palavras-chave: Violência doméstica; Agressores; Perfil; Sociojurídico; Características

\section{ABSTRACT}

This study has as general objective to define the profile of the perpetrators of violence against women under a socio-juridical aspect. It was based on the inductive method, with quantitative and qualitative approach, grounded on material archived records in the Women's Police Station of Campina Grande (PB). The research project was approved (49416415.2.0000.5175) by the Ethics Committee and the data were refined into categories for better analysis. The profile study demonstrates the need for monitoring the aggressor as envisaged by the Law, as well as greater resources by the Women's Police Station and need for disclosure on protective measures.

Keywords: Domestic violence; Offenders; Profile; Socio-juridical; Characteristics

\footnotetext{
${ }^{1}$ Graduada em Direito pela Faculdade de Ciências Sociais Aplicadas (Facisa), Campina Grande, Paraíba. Advogada, Pós Graduanda em Direito Penal e Processo Penal e Mestranda em Direito Constitucional pela Universidade Federal do Rio Grande do Norte (UFRN), Natal, Rio Grande do Norte, Brasil. Email: anaiseulalio@gmail.com

${ }^{2}$ Mestre em Direito Comunitário pela Universidade de Coimbra (UC), Coimbra, Portugal. Doutoranda em Direito Internacional na Universidade de Coimbra (UC), Coimbra, Portugal.e Professora Universitária. Email: tutortreinamneto@gmail.com
} 


\section{INTRODUÇÃO}

A perspectiva histórica sobre a mulher na sociedade mostra que sempre foi considerada como um ser vulnerável, desde mera reprodutora a instrumento de negociação - como em dotes de casamento. Os trabalhos domésticos eram obrigatórios e não havia nenhuma remuneração, como também o abastecimento da família com água, fogo e luz, cozinhar e desempenhar outras tarefas.

Com o advento da Revolução Industrial, a necessidade de maior mão-de-obra impõe a inclusão da mulher em âmbito econômico, o que acarreta sensíveis alterações na visão de mundo sobre este gênero. As mulheres passaram a conquistar seus direitos ao longo dos anos, e, na maior parte do mundo, adquiriram o direito ao voto, à escolaridade, a um lugar no mercado econômico. Entretanto, ainda assim estão longe de serem reconhecidas como iguais aos homens perante a sociedade, fato que pode ser verificado na submissão da mulher ainda existente. Mesmo diante de tantas conquistas, a sociedade se depara com a violência doméstica estampada nos mais variados meios de comunicação com grande ocorrência, praticada por membros da própria família, como também, companheiros das vítimas.

No Brasil, a violência doméstica é delimitada pela Lei nº11.340/06, mais conhecida como Lei Maria da Penha, que em seu art. $5^{\circ}$ determina que qualquer ação ou omissão baseada no gênero que cause morte, lesão, sofrimento físico ou psicológico e dano moral ou patrimonial. $\mathrm{O}$ art. $7^{\circ}$ acrescenta as formas de violências domésticas criminalmente punidas - a física, a psicológica, sexual, patrimonial e moral.

A violência doméstica abrange uma grande complexidade e seu escopo é pouco compreendido. Assim sendo, além de enxergar a sociedade como maior agressora, pode-se tentar identificar quem são os agressores dos crimes de violência doméstica com a finalidade de encontrar padrões em seus perfis para não apenas compreender melhor este acontecimento, mas ter subsídio de poder tratar e prevenir a reincidência.

Portanto, o presente estudo irá tratar sobre o perfil dos agentes de violência contra a mulher sob uma visão sociojurídica, tendo em vista a importância de compreensão da complexidade dos envolvidos no âmbito de violência doméstica.

Partindo desta premissa, diante da tutela jurídica garantida pela Lei $n^{\circ} 11.340 / 06$, bem como a atuação da Delegacia da Mulher, indaga-se quais as características do agressor em casos de violência doméstica registradas nesta instituição?

A temática proposta atende a necessidade de investigação de aspectos relacionados à violência doméstica, destacando-se a necessidade do cumprimento do art.30 da lei supracitada 
- artigo este que prevê um acompanhamento através de trabalhos e orientações concernentes à violência não apenas às vítimas, como também aos agressores. Assim, para a Lei Maria da Penha deve haver um cuidado ao agressor em paralelo ao da vítima, através de uma equipe multidisciplinar capaz de praticar medidas objetivando a recaída de crimes domésticos para uma melhor compreensão do contexto desta espécie de violência.

O presente estudo tem como objetivo geral delinear o perfil dos agressores de violência contra a mulher sob um aspecto sociojurídico; e possui como objetivos específicos identificar as causas e as situações dos crimes praticados, verificar as formas de atuação da Delegacia, e, averiguar as formas de atuação da polícia judiciária.

\section{OS DIREITOS DAS MULHERES E A LEI MARIA DA PENHA}

Apenas vários anos depois a conceituação do papel das mulheres começa a sofrer pequenas alterações, com o advento tanto da Revolução Industrial, quanto da Revolução Francesa. As mulheres tiveram uma considerável participação nessas revoluções, contribuindo como mão-de-obra e como revolucionárias a favor da igualdade, fraternidade e liberdade. Nesta época, algumas delas começaram a ter consciência que o simples fato dos seus gêneros não as limitavam, e que deveriam sim ter um lugar na sociedade como qualquer homem detinha, principalmente considerando-se que lutaram e conviveram todos juntos como iguais nessas Revoluções.

A partir disso, baseando-se na Declaração Universal dos Direitos dos Homens, e sendo observada a necessidade de criar instrumentos capazes de proteger os direitos das mulheres, a Organização das Nações Unidas (ONU) dedicou uma década - de 1976 a 1985 - para a chamada “Década da Mulher", como afirma Souza (2009). Em 1979, foi aprovado na Assembleia Geral da ONU o primeiro tratado internacional a abordar a proteção dos direitos humanos femininos, devidamente assinado e ratificado pelo Brasil, sendo ainda criado o Comitê sobre a Eliminação da Discriminação das Mulheres, que em inglês possui as siglas CEDAW, para funcionar como instrumento do tratado, criando recomendações e analisando as situações de como as mulheres estão tendo seus direitos protegidos.

Esta Convenção, de acordo com Souza (2009), apresenta um conceito que significou um grande passo: Qualquer distinção, exclusão ou restrição realizada unicamente baseada no gênero, que tenha capacidade de prejudicar as ações e direitos das mulheres, é considerada uma discriminação contra mulheres, que deve ser combatida. Vários deveres também são atribuídos aos países que assinaram e ratificaram a Convenção, devendo estes extinguir qualquer forma 
de descriminação contra mulheres, objetivando promover a igualdade entre os gêneros, assim como propor modificações nas suas legislações para que os direitos desse grupo sejam protegidos com mais afinco.

Souza (2009) defende que a partir deste período, incentivados pela CEDAW, foram criados vários outros documentos objetivando a proteção dos direitos humanos das mulheres, como a Convenção dos Direitos Políticos das Mulheres de 1952 e a Convenção sobre a Nacionalidade das Mulheres Casadas de 1957. Neste sentido, a autora enfatiza a Declaração sobre a Eliminação da Discriminação contra a Mulher - documento legal que passou a prever os direitos iguais entre homens e mulheres.

Por sua vez, no Brasil, após o movimento feminista para conseguir o sufrágio feminino, houve uma estagnação devido ao Estado Novo e à Ditadura Militar anos mais tarde, que impediu no país quaisquer reuniões populares que versassem reinvindicações, como aduz Bianchini (2009). Foi apenas em 1970 que os direitos das mulheres voltaram a ter participação no cenário político, e em grande parte foi devido à decisão da ONU de declarar a Década da Mulher, podendo ser observado, como destaca a autora, o surgimento de grupos e associações relacionadas com movimentos feministas. Em 1975, Bianchini (2009) destaca que foi criado o Movimento Feminino pela Anistia, o primeiro dessa espécie na época que perpassava o Brasil, que apresentou significantes repercussões.

A atuação dos movimentos feministas em conjunto com o Estado teve significante relevância nos anos 80, tendo sido criado inclusive o Conselho Nacional dos Direitos da Mulher (CNDM), responsável pela maior parte dos direitos humanos da mulher na Constituição Federal de 1988. Na mesma década, foi criado em São Paulo o Conselho Estadual da Condição Feminina, que possuía como principal diretriz a concepção de que a violência doméstica é um problema social, e deve ser combatida (SANTOS, 2010).

Neste diapasão, em 1985 surge a primeira Delegacia de Polícia de Defesa da Mulher do Brasil em São Paulo como uma instituição preparada para lidar com os crimes de violência doméstica contra a mulher e, para que fosse atingido o atendimento adequado às vítimas destes crimes, os funcionários devem passar por capacitações. Infelizmente, muitos políticos começaram a criar mais Delegacias da Mulher pelo Brasil pelos motivos errados, para unicamente se promoverem em campanhas eleitorais, negligenciando as medidas que deveriam ser tomadas para que mais Delegacias fossem abertas (SANTOS, 2010).

Em 1998, foi apresentada uma denúncia à Corte Interamericana de Direitos Humanos (CIDH), afirmando que o Brasil havia sido conivente com o caso de violência doméstica que teve como vítima Maria da Penha. Três anos depois, a CIDH concluiu que o Brasil havia de 
fato violado os direitos dela ao não garantir um julgamento justo e proteção judicial, recomendando que o país levasse a sério o caso, declarando sua responsabilidade por negligência, omissão e condescendência (SANTOS, 2007).

Entretanto, o Brasil permaneceu inerte em relação às recomendações e foi preciso uma petição ao Comitê que verifica a aplicação e respeito da CEDAW em 2004 informando este descumprimento de obrigações internacionais para que o governo começasse a seguir as recomendações. Em 2006, a Lei 11.340 - Maria da Penha, foi aprovada pelo Congresso Nacional.

Esta Lei foi responsável pela inspiração dos Juizados de Violência Doméstica e Familiar contra a Mulher, efetivamente criado pela resolução $\mathrm{n}^{\circ} 005$ de 20 de dezembro de 2006. Também foi criada a Promotoria de Defesa dos Direitos das Mulheres, sob o propósito de que em conjunto, essas instituições podem e devem fornecer às mulheres o devido acompanhamento e sua defesa.

\section{METODOLOGIA}

O método da pesquisa utilizado foi o indutivo, com abordagem quantitativa e qualitativa, tendo como material de base os registros arquivados na Delegacia da Mulher de Campina Grande (PB). Os dados foram coletados a partir dos Inquéritos Policiais devidamente instaurados na Delegacia, mediante portaria e/ou flagrante.

Os documentos pesquisados são sigilosos e envolvem seres humanos, portanto, o projeto de pesquisa foi aprovado (49416415.2.0000.5175) pelo Comitê de Ética do Centro de Ensino Superior e Desenvolvimento - CESED.

O procedimento baseou-se primeiramente em visitar a Delegacia da Mulher para conhecer os documentos de registro de Inquérito. Depois da aprovação do Comitê de Ética, as visitas à instituição para a coleta de dados foram intensificadas durante os meses de outubro e novembro de 2015 para consulta e coleta dos Inquéritos pertencentes ao ano de 2014. Em seguida, foi criado um banco de dados e analisado através do software Statistical Package for the Social Sciences (SPSS), versão 20.

A análise dos dados teve como parâmetro a quantificação de frequências e construção de categorias: idade, religião, estado civil, profissão, escolaridade, motivo da agressão, defesa do agressor, relação com a vítima, turno do fato, meses em que mais ocorreram crimes, dia da semana, infrações penais, prisão em flagrante, medidas protetivas e modalidades de violência segundo a lei 11.340/2006. 
Por fim, os resultados foram discutidos e respaldados na literatura pertinente, para que, então, fosse elaborado o perfil sociojurídico dos agressores de violência contra a mulher.

\section{RESULTADOS E DISCUSSÕES}

Serão abordadas considerações acerca: da coleta de dados; das características gerais do agressor; da ocorrência da prática delitiva; dos crimes cometidos; e, por fim, das medidas protetivas e da prisão em flagrante.

\subsection{DA COLETA DE DADOS}

Foram coletados dados de 585 Inquéritos Policiais na Delegacia da Mulher em Campina Grande - PB referentes ao ano de 2014. Inicialmente, foram descartados logo na fase de coleta de dados os Inquéritos que continham crimes cometidos no ano de 2013, mesmo estes tendo sido instaurados em 2014. Isto porque a análise tratada neste estudo se propôs a descrever o perfil dos agressores de violência doméstica contra a mulher a partir de casos praticados apenas durante o ano de 2014. Não foi possível ter acesso a alguns Inquéritos, pois estes estavam sendo utilizados pelos funcionários da Delegacia na época que foi realizada a coleta de dados, impossibilitando, portanto, sua inclusão.

Dos 585 Inquéritos analisados efetivamente, observou-se que 20 deles não foram concluídos em virtude de mais de uma razão - como a espera de resultado de exame de corpo de delito, a espera de carta precatória ou até mesmo quando o agressor não foi localizado e nenhum parente teve condições e informações suficientes para realizar a qualificação indireta. Como estes Inquéritos não foram devidamente concluídos por não conterem as informações necessárias dos agressores, foram também excluídos da análise.

Nos 565 Inquéritos Policiais restantes, foi observado que 52 Inquéritos pertenciam a agressores do sexo feminino, portanto correspondentes a 9,2\% dos dados. Neste sentido, Porto (2014) argumenta que são considerados os sujeitos ativos da violência doméstica e familiar contra a mulher os que por ação ou omissão pratiquem qualquer forma de violência baseandose unicamente no gênero da vítima, como determina a Lei Maria da Penha.

Assim, o autor conclui seu raciocínio com a ideia de que mulher não pode ser sujeito ativo visado pela Lei, pois seria uma forma de proteger as mulheres de forma indiscriminada e desigual, retirando da lei o propósito de proteger as pessoas do sexo feminino dos homens que aproveitam a força superior fisiológica e dos costumes sociais de se sobressair em relação às 
mulheres.

Sobre a questão de conflito de competência envolvendo mulheres no polo ativo das agressões contra outras mulheres, o Superior Tribunal de Justiça (STJ) determinou a vulnerabilidade da vítima (CC n. 88.027/MG, Relator Ministro OG FERNANDES, DJ de 18/12/2008) como um critério a mais para a caracterização da situação tratada pela Lei ${ }^{\circ}$ 11.340/2006. Desta forma, baseado em literatura científica e no julgado do STJ sobre o tema, foram desconsiderados os 52 Inquéritos que possuíam mulheres como agressoras nas situações em que não foi observada vulnerabilidade da vítima, sendo a maioria conflitos entre irmãs e sogra com nora. Ressalta-se assim que estes inquéritos não devem ser considerados de competência da Lei Maria da Penha, e, portanto, não deveriam ter sido inicialmente instaurados pela Delegacia Especializada de Defesa das Mulheres.

Além do exposto, os arts. $5^{\circ}$ e $7^{\circ}$ da Lei Maria da Penha determinam as possíveis formas de violência doméstica contra a mulher - nomeadamente a física, psicológica, sexual, moral e patrimonial -, bem como as situações em que estas formas de violência são cometidas, a saber: Âmbito doméstico, familiar e em relação íntima de afeto. Portanto, não se tratando de qualquer uma dessas formas de violência ou a ausência de convívio, vínculo familiar e relação íntima de afeto, não se configurará crime de violência doméstica e familiar contra a mulher. Em razão disso, dos 513 Inquéritos Policiais restantes, ainda foram desconsiderados dois, pois ambos relatavam casos de completos desconhecidos que assediaram e estupraram jovens mulheres, sem qualquer vínculo existente com elas.

\subsection{CARACTERÍSTICAS GERAIS DO AGRESSOR}

A tabela 1 apresenta uma síntese das características dos agressores com as principais informações acerca dos agressores de violência contra a mulher. Cada informação corresponde a uma categoria que será trabalhada e explicitada, com intuito de maior esclarecimento.

Tabela 1 - Principais características dos agressores de violência contra a mulher

\begin{tabular}{lcc}
\hline \multicolumn{1}{c}{ Características } & Frequência & Por centagem \\
\hline Alfabetizado /Ensino Fundamental & 285 & $55,8 \%$ \\
Católico & 214 & $41,9 \%$ \\
22 a 32 anos & 195 & $38,2 \%$ \\
"Ex" (namorado, marido, companheiro) & 192 & $37,6 \%$ \\
\hline \multicolumn{1}{c}{ Total } & $\mathbf{5 1 1}$ & $\mathbf{1 0 0 \%}$ \\
\hline
\end{tabular}


Fonte: Dados da pesquisa (2015).

Em relação ao nível de escolaridade dos agressores, 55,8\% deles estudaram até o Ensino Fundamental, como observado na tabela 01, podendo ter concluído ou não - pois a Delegacia não oferece maiores informações de quantos anos foram estudados.

Não obstante, encontra-se resultados similares em outros estudos como o de Deekee et al (2009) em sua pesquisa sobre os agressores de violência doméstica em Florianópolis (SC), apontando que $40 \%$ deles tinham apenas o Ensino Fundamental Incompleto, à medida que Griebler e Borges (2013) encontraram 69,3\% de agressores no nível Fundamental, completo e incompleto.

No tocante a religião, quando relacionada com violência contra a mulher, Cavalcanti (2005) ressalta a religião muçulmana, que confere às mulheres diversas restrições de direitos fundamentais. Entretanto, como bem alega o autor, a situação não se aplica apenas a esta religião.

Nota-se um número alto de agressores que se denominam cristãos, em geral, praticando atos violentos contra as mulheres. Ou seja, vislumbra-se que apesar dos 237 agressores se declararem como crentes (somados os que se declaram Cristãos, Católicos, Evangélicos e Espíritas), o poder dos costumes sociais de sentir o homem como ser superior se sobressai à religião e seus preceitos.

Sobre estes dados comentados, é importante destacar que em grande parte dos Inquéritos Policiais, estas categorias não foram preenchidas. Na grande parte dos Inquéritos com Autos de Prisão em Flagrante (APF), os agressores não foram inqueridos sobre a religião e nem sobre o nível de escolaridade, enquanto em outros possuía Boletim Individual que apresentava estas informações.

A idade média dos agressores em questão foi de 35,25 anos ( $\mathrm{DP}=10,44 ; \min =18$; max=72). Resultado similar também foi encontrado em pesquisa desenvolvida por Griebler e Borges (2013), pois a idade média encontrada foi acima de 35 anos.

Observou-se que dos agressores que cometeram violência doméstica durante o ano de 2014 e que foram notificados na Delegacia da Mulher, 38,2\% correspondem à faixa etária de 22 a 32 anos, corroborando com a análise de Sousa, Nogueira e Gradim (2013). Neste estudo, $32 \operatorname{anos}(73,2 \%)$ foi a idade de maior frequência em que os agressores possuíam quando da data em que o crime foi notificado.

Dessa forma há uma clara disparidade no percentual de agressores idosos, com apenas 2,2\%. Em relação à faixa etária correspondente a idosos, Souza e Nery (2014) chegaram a uma 
porcentagem semelhante, em que os idosos são em 2,44\% responsáveis por praticar violência contra a mulher. Na grande maioria dos casos em que homens idosos agridem mulheres, estas são suas esposas ou companheiras, também idosas.

Sobre mulheres idosas vítimas de violência, de acordo com Sousa et al (2010), a maior parte dos crimes contra idosas são direcionadas às Delegacias Especializadas de Defesa dos Direitos da Mulher, mesmo nos casos em que os agressores e as situações não se classifiquem como violência doméstica contra a mulher de fato.

Considerando os dados dispostos, é notório que os agressores, na sua maioria, se classificam como "Ex" de suas vítimas. Estes resultados corroboram com os estudos de Lamoglia e Minayo (2009) em uma cidade o Rio de Janeiro, em que os ex-companheiros, maridos e companheiros são responsáveis pelo maior número de agressões de violência doméstica.

A tabela 2 demonstra os resultados acerca das profissões dos agressores, o que ajuda na identificação do perfil. Foram divididas em categorias e demonstradas as que contavam com no mínimo dez agressores que responderam a mesma profissão - ou seja, os que responderam as variantes de "operador", como operador de produção, mistura e betoneira não entram na categoria "operador de máquinas", como exposto a seguir.

Tabela 2- Profissões dos agressores de violência doméstica do estudo

\begin{tabular}{lcr}
\hline \multicolumn{1}{c}{ Profissões } & Prequência & \\
\hline Pedreiro & $\mathbf{4 6}$ & $\mathbf{9 \%}$ \\
Comerciante & 25 & $\mathbf{4 , 9 \%}$ \\
Operador de Máquinas & 20 & $\mathbf{3 , 9 \%}$ \\
Serviços Gerais & 20 & $\mathbf{3 , 9 \%}$ \\
Mototaxista & 17 & $\mathbf{3 , 3 \%}$ \\
Servente de Pedreiro & 16 & $\mathbf{3 , 1 \%}$ \\
Motorista & 16 & $\mathbf{3 . 1 \%}$ \\
Vendedor & 15 & $\mathbf{2 , 9 \%}$ \\
Desempregado & 15 & $\mathbf{2 , 9 \%}$ \\
Vigilante & 14 & $\mathbf{2 , 7 \%}$ \\
Desocupado & 13 & $\mathbf{2 , 5 \%}$ \\
Pintor & 13 & $\mathbf{2 , 5 \%}$ \\
Aposentado & 12 & $\mathbf{2 , 3 \%}$ \\
Agricultor & 12 & $\mathbf{2 , 3 \%}$ \\
Estudante & 11 & $\mathbf{2 , 2 \%}$ \\
Outros & & \\
\hline Total & $\mathbf{2 4 6}$ & $\mathbf{4 7 , 8 \%}$ \\
\hline
\end{tabular}

Fonte: Dados da pesquisa (2015).

Imediatamente, a categoria profissional que se destaca é a de Pedreiro, tendo 46 homens agressores de mulheres nesta investigação. Quando observada a categoria de Servente de 
Pedreiro, intrinsecamente ligada à atividade de pedreiro, nota-se como essas duas profissões representam muito dos agressores de violência doméstica e familiar. De acordo com o portal de notícias "Portal do Dia" (2012), um estudo elaborado em Teresina (PI), no ano de 2012, sobre violência doméstica contra a mulher, foi também evidenciado que a maior quantidade de agressores possuía como profissão, a de pedreiro.

Ainda em uma análise geral, percebe-se que dentre as 15 categorias específicas expostas, 14 delas representam profissões em que não há necessidade de alto nível de instrução, o que corrobora com os dados apresentados anteriormente, em que é demonstrado que a maioria dos agressores possui nível até o Ensino Fundamental.

Como Moura et al (2009) afirmam, a maior parte das notícias-crime comunicadas na Delegacia são advindas de pessoas com baixo nível de escolaridade, porém, é válido salientar que a violência doméstica acontece em todo os grupos sociais, com agressores de todos os níveis de escolaridade e profissão. A exemplo disso, temos a presença de agressores profissionais com curso superior a exemplo de advogados, professores e médicos inseridos na categoria Outros - entretanto, em bem menor quantidade.

\subsection{DA OCORRÊNCIA DA PRÁTICA DELITIVA}

A tabela 3 apresenta as informações acerca da ocorrência da prática delitiva, apresentando as principais informações quanto aos motivos que apareceram com mais frequência, também sendo abordado a defesa que o agressor apresentou na Delegacia.

Tabela 3 - Motivos que levaram os agressores a praticarem violência doméstica e familiar

\begin{tabular}{lcc}
\hline Motivos & Frequência & Porcentagem \\
\hline Discussão & 112 & $21,9 \%$ \\
Bebida & 104 & $20,4 \%$ \\
Não aceita separação & 59 & $11,5 \%$ \\
Ciúme & 54 & $10,6 \%$ \\
Imotivado & 46 & $9 \%$ \\
Dinheiro & 29 & $5,7 \%$ \\
Uso de Drogas & 16 & $3,1 \%$ \\
Outros & 91 & $17,8 \%$ \\
\hline \multicolumn{1}{c}{ Total } & $\mathbf{5 1 1}$ & $\mathbf{1 0 0 \%}$ \\
\hline
\end{tabular}

Fonte: Dados da pesquisa (2015).

O grande motivo alegado que causou as agressões foi "Discussão", em sentido amplo. Em sentido estrito, as discussões variaram muito, ora sair de casa sem lhe avisar, até mesmo discordar da forma em que ela (a mulher) cuida dos filhos. As agressões ocorreram durante ou logo após as discussões, fazendo com que esta categoria seja explicada pelo domínio do calor da emoção no momento. 
A bebida alcóolica surge em segundo lugar na frequência, no entanto, resta questionar o que possa ter surgido primeiro - a discussão ou a ingestão de bebida. Neste sentido, Sousa, Nogueira e Gradim (2013) ressaltam que o abuso de bebidas alcóolicas é uma das principais causas de agressões no âmbito da violência doméstica, sendo comum em eventos familiares, comemorações e também utilizada em momentos de dor e sofrimento. Segundo Gribler e Borges (2013), o alto número de consumo de bebidas alcóolicas é compreendido pelo costume social, herdado de outras sociedades o uso de álcool principalmente em relação aos homens.

É inegável que o efeito das bebidas alcóolicas afeta negativamente o organismo do ser humano, contribuindo com seu comportamento mais violento, assim como as drogas ilícitas. Entretanto, as drogas ilícitas aparecem em número bem menor do que a bebida $(3,1 \%)$, provavelmente em razão do desconhecimento da vítima sobre o uso e vício destas drogas ilícitas pelos agressores.

O Ciúme originou também um alto número de agressões, sendo ele na maior parte dos casos advindos do próprio agressor, e uma menor quantidade sobrevinda das vítimas. Quando é a mulher que sente ciúmes, não é difícil perceber que geralmente elas notificam o crime apenas para ganhar atenção do companheiro, havendo, neste cenário, muitas desistências até mesmo antes da peça inicial acusatória.

O portal de notícias online do Senado Federal em 2015 apresenta uma pesquisa realizada pela central de atendimento pelo telefone, durante junho e julho deste ano, em consonância com os resultados de que Bebida e Ciúme configuram como principais agentes causadores de violência doméstica e familiar contra as mulheres. Portanto, estes dados levam a acreditar que o consumo de bebida alcoólica potencializa a discussão e o ciúme.

Quanto aos agressores, ao serem interrogados na Delegacia da Mulher, eles possuem oportunidade de se defender, explicando a ocasião que culminou com a notificação por parte da vítima ou algum outro familiar dela. Dessa forma, a defesa que os agressores apresentam na fase de investigação, é importante para melhor subsidiar a compreensão sobre o motivo, na ótica dos agressores o que aconteceu.

Como geralmente esperado, a grande maioria negou as alegações das vítimas $(58,5 \%)$, enquanto $23,5 \%$ preferiram se reservar ao direito do silêncio. Os agressores que de fato confessaram os crimes $(12,7 \%)$, comumente o fizeram com uma ressalva: praticaram em legítima defesa. Sobre o assunto, a doutrina majoritária defende que legítima defesa para os agressores raramente acontece efetivamente.

Explicita-se que, mesmo que os comportamentos das vítimas tenham o condão de provocar seus agressores, estes, como pertencentes do gênero masculino, devem agir 
proporcionalmente com sua força. Não há, por exemplo, legítima defesa quando a mulher dá uma tapa e o agressor reage com um murro, um chute e uma ameaça.

A categoria Imotivado refere-se a todos os Inquéritos Policiais que não conseguiram extrair das vítimas o motivo específico que tenha originado e causado as agressões, por exemplo, sendo narrado nos relatórios finais apenas que "de maneira imotivada, Fulano agrediu a vítima".

Nos estudos existentes sobre o perfil de agressores pelo Brasil, sempre há referência do período em que mais ocorrem agressões no âmbito de violência doméstica. Portanto, seguindo essa linha, para um melhor panorama, foi elaborado um gráfico de barras de acordo com a frequência de crimes e os meses notificados em Campina Grande, observados em seguida.

Gráfico 1- Relação entre a frequência e crimes de violência doméstica notificados no decorrer dos meses

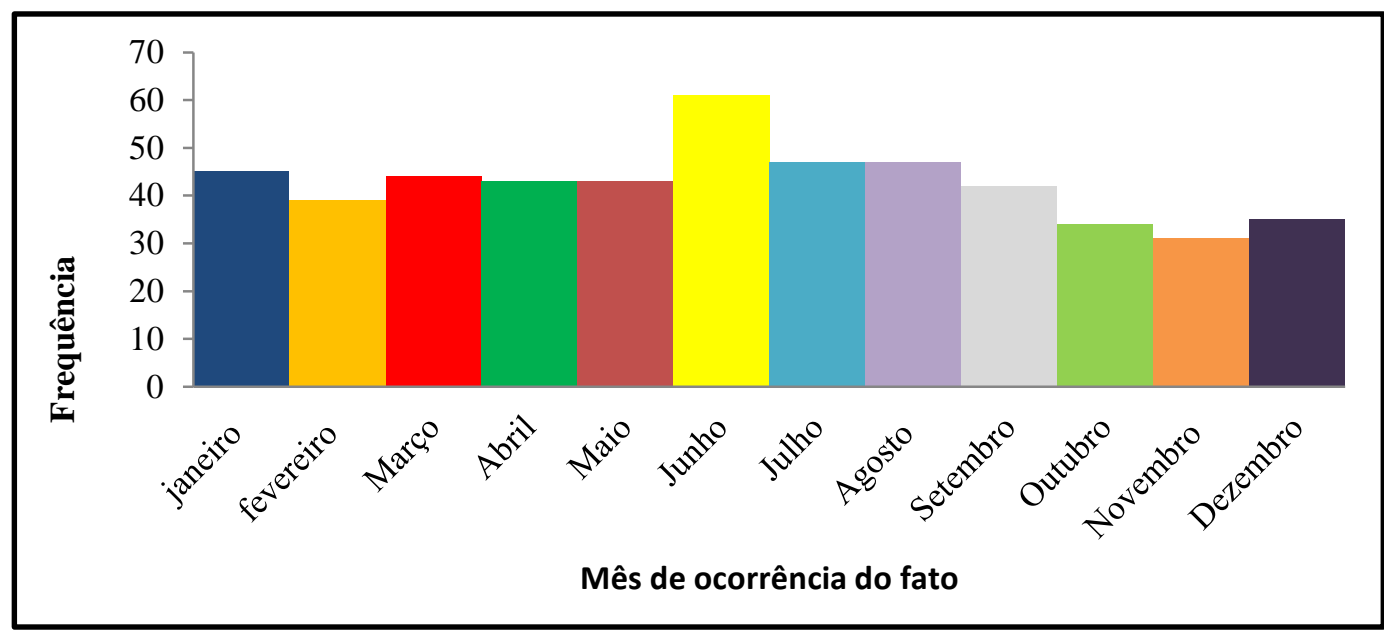

Fonte: Dados da pesquisa (2015)

Podemos observar que no mês de junho ocorreram mais crimes de violência doméstica em Campina Grande, com uma frequência de 61 casos, representando 11,9\% do total dos casos em análise para doze meses. Esse resultado é decorrente dos 30 dias de festa do 'Maior São João do Mundo', que acontece todos os anos no Parque do Povo durante todo o mês de junho, sendo o evento mais tradicional e reconhecido da cidade por todo o país. O pensamento lógico indica que o fato da festa de São João ocorrer diariamente todo o mês ocasiona um maior uso de substâncias recreativas legais e ilegais, o que, inegavelmente, contribui para a ocorrência de crimes de violência doméstica.

O presente estudo difere quanto ao assunto em relação a pesquisa de Sousa, Nogueira e Gradim (2013), em que chegaram ao resultado de que os meses em que mais aconteceram crimes de violência doméstica e familiar em um município de Minas Gerais, e, que foram 
notificados na Delegacia, foram nos meses de Janeiro a Março.

Assim como vimos as notificações de crimes distribuídos nos meses do ano, foi analisado também o dia da semana em que mais foi frequente a ocorrência de crimes notificados, conforme o seguinte gráfico.

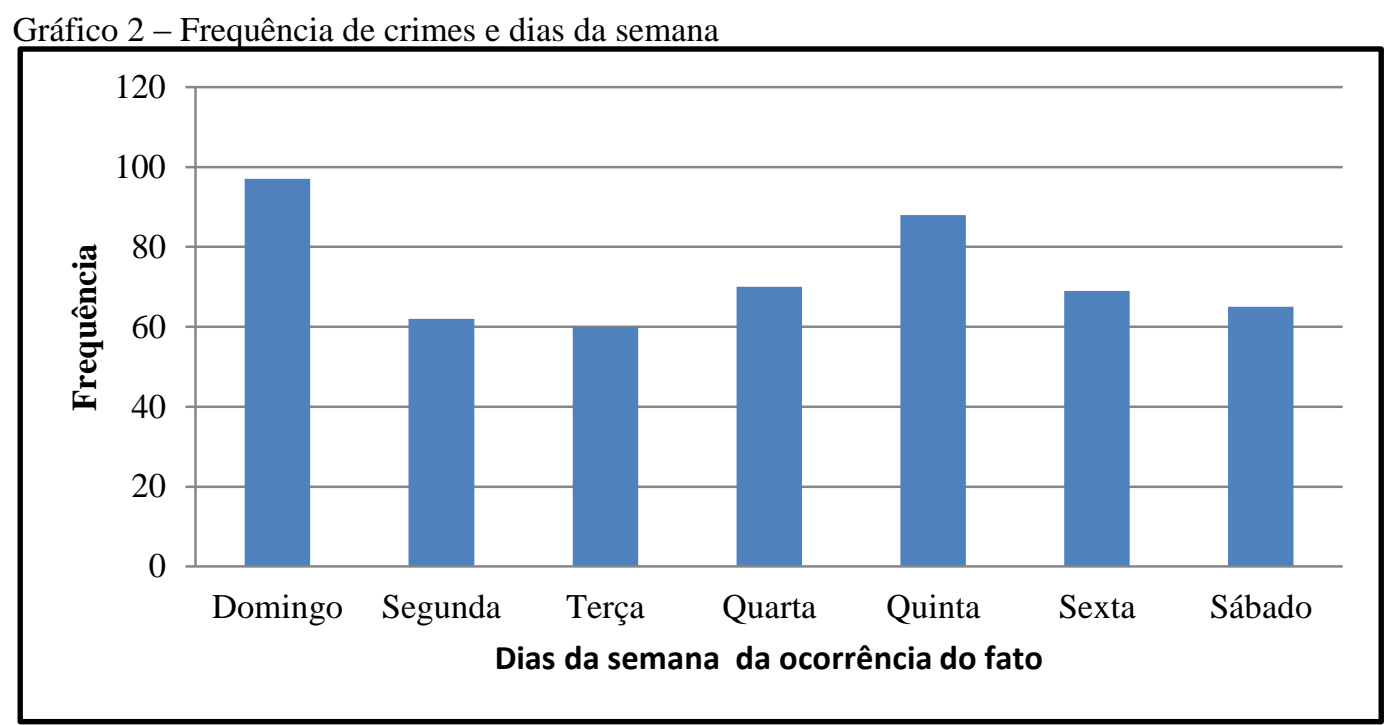

Fonte: Dados da pesquisa (2015).

Mais uma vez, a presente pesquisa difere um pouco das demais já existentes, apresentando o Domingo (19\%) como o dia da semana em que mais são praticados crimes de violência doméstica e familiar contra a mulher, e, logo em seguida, a Quinta-feira com 88 casos, representando $17,2 \%$. Os dias da semana que mais são frequentes o registro de acontecimento da violência doméstica relatados nos estudos de Mesquita (2010), são os finais de semana, Sábado e Domingo, assim como Griebler e Borges (2013) e Sousa, Nogueira e Gradim (2013).

Houve provável influência neste resultado quanto ao dia da semana pela ocorrência do festejo diário do Maior São João do Mundo. Ainda, a quinta-feira pode ser vista como o início do final de semana e, portanto, uma maior "liberdade" para exageros etílicos ou no uso de outras substâncias.

Verifica-se ainda neste estudo, que o turno em que aconteceram as ocorrências notificadas vai em sentido contrário à referência literária que expõe o horário da noite como o 
de maior ocorrência.

O turno com maior frequência e representando $73,8 \%$ do total foi o Diurno, que compreende tanto as ocorrências matutinas quanto vespertinas, enquanto o noturno conta com $22,3 \%$ e o turno da madrugada com apenas 3,9\%. É algo bastante curioso a ser estudado com mais afinco, pois leva-nos a presumir que houve mais ocorrências durante o dia porque os agressores estavam com as vítimas nos respectivos horários, e não no trabalho.

Garbini et al (2011) demonstram em sua pesquisa como o período noturno foi mais frequente, sobretudo nos finais de semana. Este resultado, segundo os autores, se justifica principalmente por ser o período correspondente que os agressores mais ficam em casa em contato com a vítima. Outros estudos apontam para o mesmo resultado (SOUSA; NOGUEIRA; GRADIM, 2013), demonstrando como esta pesquisa em Campina Grande obteve resultados diferenciados.

\subsection{DOS CRIMES COMETIDOS}

Como já mencionado anteriormente neste estudo, a Lei no 11.340/2006 traz, em se art. $7^{\circ}$, a tipologia da violência doméstica em cinco grupos: física, psicológica, sexual, patrimonial e moral, como explicitam Sarmento e Cavalcanti (2009). A violência física configura-se como a que atinge a integridade física e a saúde da vítima, enquanto a psicológica, qualquer agressão que provoque à vítima danos emocionais que sejam capazes de prejudicar a vida desta.

Já a violência sexual consiste em qualquer ação que obrigue a vítima a manter ou participar de relações sexuais não desejadas com o autor do crime, enquanto a patrimonial consiste em qualquer agressão que afete os bens patrimoniais e econômicos das vítimas. A violência moral é a que afeta a honra subjetiva e objetiva da vítima.

Nesta pesquisa, os Inquéritos analisados possuem em sua grande maioria, mais de um crime por pessoa, possibilitando, portanto, que um mesmo agressor tenha chegado a praticar até cinco delitos em concurso material. Assim, os números de crimes são superiores aos números dos inquéritos. O gráfico abaixo demonstra a frequência das modalidades de violência. 
Gráfico 3 - Modalidades de violência cometidas a partir da frequência

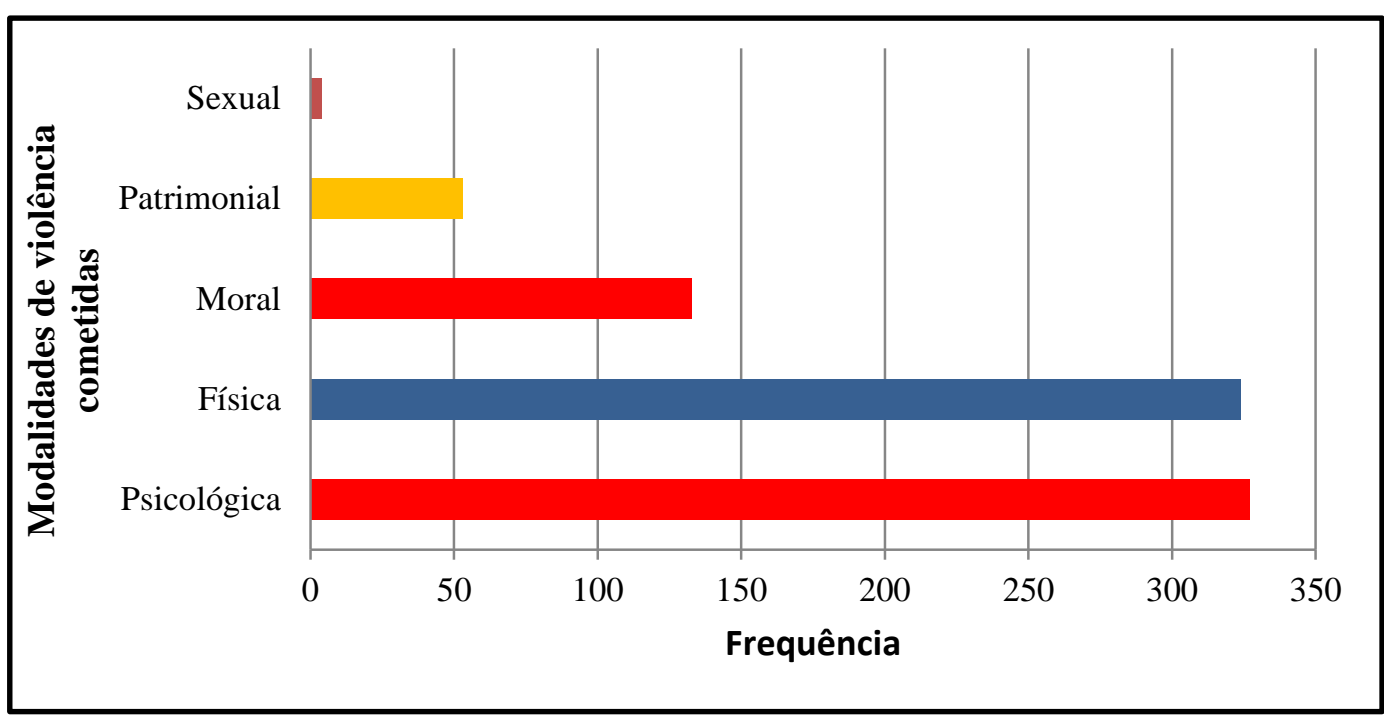

Fonte: Dados da pesquisa (2015).

O gráfico demonstra como a violência física e a psicológica foram muito praticadas, aparecendo 324 e 327 vezes, respectivamente. A violência física compreende os crimes de homicídio, lesão corporal- que, sozinha, foi observada em 119 casos-, maus tratos e a contravenção penal de vias de fato. Quanto a psicológica, só o crime de ameaça, individualmente, foi analisado em 88 casos. Esta também envolve a contravenção penal de perturbação.

Salienta-se que o crime de lesão corporal é analisado a partir de duas formas, como explicita Porto (2014): genérica e específica. A forma genérica é representada no art. $129, \S 9^{\circ}$ do Código Penal Brasileiro, que trata da lesão corporal em âmbito doméstico, não especificando gêneros - sendo, portanto, atribuída tanto a homens quanto mulheres. Nesta ocasião, é possível a aplicação da Lei de Juizados Especiais Criminais. Por outro lado, a forma específica é o art. $129, \S 9^{\circ}$ do Código Penal em combinação com os artigos $5^{\circ}$ e $7^{\circ}$ da Lei $n^{\circ} 11.340 / 06$ - sendo esta específica para as vítimas do gênero feminino.

Percebe-se desde já que, com a pequena disparidade entre essas duas modalidades de violência, a violência psicológica destaca-se um pouco mais do que a física e muito mais do que as outras modalidades de violência, resultado diferenciado de pesquisas já existentes que marcam a física como a modalidade mais frequente, como é o caso do estudo Labronici et al (2010).

A violência moral vem em seguida, com uma diferença grande em relação às duas primeiras, tendo sido praticada 133 vezes. Dentre os crimes contra a honra, apenas a injúria 
aparece sozinha, num total de seis vezes. A violência patrimonial marcou sua presença em 53 casos, envolvendo crimes de violação de domicílio, extorsão e dano.

Por outro lado, a violência sexual foi notificada em apenas quatro casos. Dantas-Berger e Giffin (2005) relatam em seu estudo que este tipo de violência sexual é muito praticado, porém, pouco relatado nas Delegacias das Mulheres - chegando, inclusive, a ser um fenômeno despercebido diante de sua invisibilidade. Os autores explicam que isto corre devido às barreiras socioculturais, que coíbem as mulheres a falar sobre o assunto e contribui até mesmo com o pensamento de que violência sexual não é crime, mas apenas a normalidade.

\subsection{MEDIDAS PROTETIVAS E PRISÃO EM FLAGRANTE}

A prisão em flagrante em casos que se adequem ao Juizado Especial Criminal (Lei ${ }^{\circ}$ 9.099) não é cabida, devido aos crimes insertos nesta lei serem de menor potencial ofensivo, devendo a autoridade policial apenas lavrar um Termo Circunstanciado de Ocorrência (TCO). Entretanto, por ser afastada esta Lei para o caso de violência doméstica, é plenamente possível a prisão em flagrante dos agressores caso encontrem-se em estado de flagrância.

Assim, a prisão em flagrante possui natureza cautelar, como afirma Lima (2012), com caráter de autodefesa para a sociedade. Em razão de ela admitir ser realizada por qualquer pessoa, apenas a autoridade policial possui competência para lavrar o Auto de Prisão em Flagrante (APF).

Nesta investigação, percebe-se que apesar da maioria dos casos os agressores não terem sido presos em flagrante $(70,8 \%)$, uma porcentagem importante foi, refletindo que em $29,2 \%$ os Policiais conseguiram chegar à cena do crime na hora que estava acontecendo ou pelo menos, logo após. Dos 149 que foram presos, 135 pagaram fiança de acordo com suas situações financeiras.

A Lei Maria da Penha, para dar um apoio maior às vítimas de violência doméstica e familiar, prevê medidas cautelares de urgência - as chamadas Medidas Protetivas. Sarmento e Cavalcanti (2009) ressaltam a importância destas no âmbito em comento: Elas podem ser diferidas pelo Juiz do Juizado de Violência Doméstica e Familiar Contra a Mulher ou pelo Juiz Criminal (na ausência de Juizado específico) antes mesmo do processo se iniciar, sem precisar que os agressores sejam escutados.

Apesar de ser um número expressivo que representa as ocasiões em que as vítimas requereram alguma medida protetiva de urgência $(24,5 \%)$, esperava-se que fosse maior a frequência, tendo em vista quão inovadora a medida é para proteger as vítimas. Labronici et al 
(2010) defendem que as vítimas de violência doméstica não denunciam os agressores para vêlos sendo punidos, e sim, para que recuperem a relação com o agressor anterior.

\section{CONSIDERAÇÕES FINAIS}

A partir dos resultados analisados nesta investigação, pode-se concluir que os homens agressores de mulheres em Campina Grande possuem um perfil semelhante aos perifs traçados em outros estudos e em outros municípios, porém, com sensíveis distinções no tocante a prática delitiva.

Além das bebidas alcóolicas e dos ciúmes, amplamente abordados nas pesquisas sobre violência doméstica, os fatos verificados com frequência neste perfil de agressores, referem-se aos motivos de discussão e de não aceitar a separação com a vítima.

Com relação às causas e situações dos crimes praticados, observou-se que não precisa haver motivos fortes que provoquem as agressões, mas sim, simples atos e palavras. Quanto à defesa elaborada pelos próprios agressores, verificou-se que grande parte negou os crimes, poucos confessaram e uma parcela permaneceu calada, justificando seus atos na legítima defesa.

Neste estudo, o que mais se destacou dos demais pesquisados foi o dia da semana em que o crime foi ocorrido, bem como o mês e o turno que mais foi frequente. Em razão da festa junina que acontece todos os anos durante 30 dias initerruptamente na cidade de Campina Grande, com liberação do consumo de bebidas alcóolicas, possibilita o incentivo à prática de agressões domésticas e familiares, concentrando o mês de junho como o mais frequente número de ocorrências notificadas de agressão doméstica. Quanto ao turno, exige-se um estudo mais profundo sobre o motivo de que em Campina Grande, os crimes acontecem mais frequentemente no período diurno, quando, ao contrário dos estudos pesquisados, estes ocorrem no período noturno.

Os agressores praticaram múltiplos e variados tipos de violência doméstica, tendo a violência psicológica a maior frequência e a sexual como menor. Nesta questão, ressalta-se a importância da divulgação sobre o que se configura como violência doméstica, com o desígnio de informar à sociedade que não apenas as agressões físicas que são crimes, como também a psicológica, moral, patrimonial e sexual.

Foi verificada a eficácia da atuação da Polícia quanto às prisões em flagrante, observando-se a frequência em que ocorreu, demonstrando que, quando solicitada no momento adequado, ela de fato protege as vítimas. Quanto às medidas protetivas, imagina-se que deveria haver mais divulgação das informações sobre elas na sociedade, tendo em vista o alto número 
de notificação de crimes e um número menor em relação às solicitações de medidas protetivas.

Além disso, observa-se uma necessidade do cumprimento do art. 30 da Lei Maria da Penha com a finalidade de criar grupos reflexivos destinados aos agressores com uma equipe multidisciplinar que possa colaborar de forma efetiva com a não reincidência. No Brasil, há experiências com a utilização desses grupos que foram eficazes para ampliar a visão de mundo dos agressores, que devem ser adotadas e seguidas pelas demais regiões.

Deve-se ressaltar que uma análise mais profunda das características dos agressores foi prejudicada pela ausência de informações, mesmo estas sendo requisitadas nos Boletins Individuais. Fato que também prejudicou esta pesquisa, foram os dados respondidos incorretamente, sem referências completas do local onde residem, a quantidade de filhos, a que religião que professam. A ausência de acompanhamento aos agressores pela Delegacia também é preocupante.

Finalmente, o trabalho de pesquisa não se finda, ele leva a outras problematizações, outras buscas de compreensão. Esta pesquisa aponta para a efetivação da Lei no 11.340/2006, mas demonstra também que os órgãos públicos envolvidos como as delegacias, carecem de uniformização de dados e inter-relação com outros órgãos similares, onde se pudesse conhecer mais sobre o agressor, repassar para outro setor acompanha-lo no intuito de reinseri-lo no mundo da não violência doméstica e familiar contra a mulher.

\section{REFERÊNCIAS}

BIANCHINI, A. A luta por direitos das mulheres. Jornal Carta Forense, 2009. Disponível em: http://www.cartaforense.com.br/conteudo/artigos/a-luta-por-direitos-das-mulheres/ 3858 . Acesso em: 01 jun. 2015.

BRASIL. Lei ${ }^{\circ}$ 11.340/2006: Lei Maria da Penha de 7 de agosto de 2006. Brasília: Senado, 2006. Disponível em: ttp://www.planalto.gov.br/ccivil_03/_ato2004-2006/2006/lei/111340. htm. Acesso em: 15 nov. 2015.

Norma técnica de padronização: Delegacias Especializadas de Atendimento à Mulher - DEAMs. Brasília: Ministério da Justiça, 2006.

CAVALCANTI, S. V. S. F. A violência doméstica como violação dos direitos humanos. Revista Jus Navigandi, Teresina, ano 10, n. 901, 21 dez. 2005. Disponível em: http://jus. com.br/artigos/7753. Acesso em: 17 nov. 2015.

DANTAS-BERGER, S. M.; GIFFIN, K. A violência nas relações de conjugalidade: invisibilidade e banalização da violência sexual? Caderno de Saúde Pública, v. 21, n. 2, p. 417-425, 2005. 
DEEKEE, L. P. et al. A dinâmica da violência doméstica: uma análise a partir dos discursos da mulher agredida e de seu parceiro. Rev. Saúde Soc, v. 18, n. 2, p. 248-258, abr./jun. 2009.

GARBIN, C. A. S. et al. Violência denunciada: ocorrências de maus tratos contra crianças e adolescentes registradas em uma unidade policial. Revista Brasileira de Enfermagem, Brasília, v. 64, n. 4, p. 665-670, ago. 2011. Disponível em: www.scielo.br/scielo. php?script =sci_arttext\&pid=S0034-71672011000400006\&lng=en\&nrm=iso. Acesso em: 21 nov. 2015.

GRIEBLER, C. N.; BORGES, J. L. Violência contra a mulher: perfil dos envolvidos em boletins de ocorrência da Lei Maria da Penha. Revista Psico on-line, v. 44, n. 2, p. 215-255, abr./jun. 2013. Disponível em: https://revistaseletronicas.pucrs.br/ojs/index.php/revistas psico/article/viewFile/11463/9640. Acesso em: 22 nov. 2015.

LABRONICI, L. M. et al. Perfil da violência contra mulheres atendidas na Pousada de Maria. Revista Escola de Enfermagem USP, São Paulo, v. 44, n. 1, p. 126-133, mar. 2010. Disponível em: $\quad$ http://www.scielo.br/scielo.php?script=sci_arttext\&pid=S0080-623420 10000100018\&lng=en\&nrm=iso. Acesso em: 23 nov. 2015.

LAMOGLIA, C. V. A.; MINAYO, M. C. S. Violência conjugal, um problema social e de saúde pública: estudo em uma delegacia do interior do Estado do Rio de Janeiro. Revista de Ciência Saúde Coletiva, Rio de Janeiro, v. 14, n. 2, p. 595-604, abr. 2009. Disponível em: http://www.scielo.br/scielo. Acesso em: 20 nov. 2015.

LIMA, F. R. de. Fiança policial, violência doméstica e nova Lei das Prisões. Revista Jus Navigandi, Teresina, ano 17, n. 3264, 8 jun. 2012. Disponível em: http://jus.com.br/ artigos/21962. Acesso em: 22 nov. 2015.

MESQUITA, A. P. As Marias que não calam: perfil das mulheres vítimas de violência após a implementação da Lei Maria da Penha em Maceió/AL. Florianópolis: Universidade Federal de Santa Catarina, 2010. Disponível em: http://www.fazendogenero.ufsc.br/9/resources/ anais/1278269236_arquivo_texto_competo_asmariasfg9.pdf. Acesso em: 20 nov. 2015.

MOURA, L. B. A. et al. Violências contra mulheres por parceiro íntimo em área urbana economicamente vulnerável, Brasília, DF. Revista Saúde Pública, São Paulo, v. 43, n. 6, p. 944-953, dez. 2009. Disponível em: http://www.scielo.br/scielo.php?script=sci_arttext\& pid=S0034-89102009000600005\&lng=en\&nrm=iso. Acesso em: 20 nov. 2015.

PASSOS, V. Agressores de esposas estão em todas as classes sociais, mas perfil majoritário é da periferia. Piauí: Portal, 2013. Disponível em: http://www.portalodia. com/noticias /piaui/agressores-de-esposas-estao-em-todas-as-classes-sociais-mas-perfil-majoritario-e-daperiferia-169739.html. Acesso em: 20 nov. 2015.

PORTO, P. R. F. Violência doméstica e familiar contra a mulher: lei 11.340/06 - análise crítica e sistêmica. 3. ed. Porto Alegre: Livraria do Advogado Editora, 2014.

RODRIGUES, A. Participação política das mulheres e gestão em política de gênero. Brasília: CFemea, 2004. Disponível em: http://cfemea.org.br/temasedados/detalhes.asp?IDTemas Dados=92. Acesso em: 21 maio 2015.

SANTOS, C. M. Da delegacia da mulher à Lei Maria da Penha: absorção/tradução de demandas 
feministas pelo Estado. Revista Crítica de Ciências Sociais Online, n. 89, 2010. Disponível em: http://rccs.revues.org/3759. Acesso em: 09 jun. 2015.

Ativismo jurídico transnacional e o Estado: reflexões sobre os casos apresentados sobre o Brasil na Comissão interamericana de Direitos Humanos. SUR: Revista Internacional de Direitos Humanos, São Paulo, v. 4, n. 7, 2007. Disponível em: http://bdjur.stj.jus.br//dspace/handle/2011/18136. Acesso em: 20 set 2016.

SARMENTO, G.; CAVALCANTI, S. Violência doméstica e assédio moral contra as mulheres. Maceió: EDUFAL, 2009.

SOUSA, A. K. A. de; NOGUEIRA, D. A.; GRADIM, C. V. C. Perfil da violência doméstica e familiar contra a mulher em um município de Minas Gerais, Brasil. Caderno de Saúde Coletiva, v. 21, n. 4, p. 425-431, 2013.

SOUSA, D. et al. Maus-tratos contra idosos: atualização dos estudos brasileiros. Revista Brasileira de Geriatria e Gerontologia, Rio de Janeiro, v. 13, n. 2, ago. 2010. Disponível em: http://revista.unati.uerj.br/scielo.php?script=sci_arttext\&pid=S1809-98232010000200 016\&lng=pt\&nrm=iso. Acesso em: 18 nov. 2015.

SOUZA, D. F.; NERY, I. S. Políticas públicas e os agressores das mulheres vítimas de violência doméstica e familiar. Recife: Universidade Federal de Pernambuco, 2014.

SOUZA, M. C. Os direitos humanos das mulheres sob o olhar das Nações Unidas e o Estado Brasileiro. Revista Âmbito Jurídico, Rio Grande, v. 12, n. 63, abr. 2009. Disponível em: http://www.ambito-juridico.com.br/site/index.php?n_link=revista_artigos_leitura \&artigo_ $\mathrm{id}=6095$. Acesso em: 19 maio 2015.

VASCO, P. S. Ciúme e álcool estimulam violência contra a mulher, revela pesquisa do Data Senado. Senado Notícias, Brasília, set. 2015. Disponível em: <http://www12.senado. leg.br/noticias/materias/2015/09/08/ciume-e-alcool-estimulam-violencia-contra-a-mulherrevela-pesquisa-do-datasenado . Acesso em: 21 nov. 2015. 